\title{
Prognostic value of neuron-specific enolase for small cell lung cancer: a systematic review and meta-analysis
}

Zhoujunyi Tian, Chaoyang Liang, Zhenrong Zhang, Huanshun Wen, Hongxiang Feng, Qianli Ma, Deruo Liu and Guangliang Qiang* (1)

\begin{abstract}
Background: Neuron-specific enolase (NSE) has become a widely used and easily attainable laboratory assay of small cell lung cancer (SCLC). However, the prognostic value of NSE for SCLC patients remains controversial. The aim of the study was to evaluate the correlation between elevated serum NSE before therapy and survival of SCLC patients.

Methods: We performed a systematic review and meta-analysis. A systematic literature search was conducted in PubMed, Embase, and the Cochrane Central Register from the inception dates to December 2019. Eligible articles were included according to inclusion and exclusion criteria; then, data extraction and quality assessment were performed. The primary outcome was overall survival (OS), and the secondary endpoint was progression-free survival (PFS).
\end{abstract}

Results: We identified 18 studies comprising 2981 patients. Pooled results revealed that elevated NSE was associated with worse OS ( $H R=1.78,95 \% \mathrm{Cl} 1.55-2.06, p<0.001)$ and PFS ( $\mathrm{HR}=1.50,95 \% \mathrm{Cl} 1.16-1.93, p=0.002)$. In subgroup analysis, elevated NSE did not predict worse OS in patients who received only chemotherapy (HR 1.22, $95 \% \mathrm{Cl} 0.96-1.55, p=0.10$ ) or part of whom received surgical resection before chemotherapy and radiotherapy $(\mathrm{HR}=2.16,95 \% \mathrm{Cl} 0.82-5.69, p=0.12)$.

Conclusion: Elevated serum NSE before any therapy of SCLC patients may be a negative prognostic factor for OS and PFS. The prognostic value of NSE for OS was particularly observed in patients treated by standard management.

Keywords: Neuron-specific enolase, Small cell lung cancer, Prognosis, Meta-analysis

\section{Background}

Lung cancer is the leading cause of cancer-related death throughout the world [1]. Small cell lung cancer (SCLC) is a deadly tumor accounting for approximately $15 \%$ of lung cancers [2]. And it is pathologically, molecularly, biologically, and clinically different from non-small cell lung cancer (NSCLC). According to whether the tumor

\footnotetext{
* Correspondence: pkudd@126.com

Department of Thoracic Surgery, China-Japan Friendship Hospital, \#2 Yinghua East Road, Chaoyang District, Beijing 100029, China
}

is with distant metastasis and can be safely treated with definitive radiation doses, SCLC patients were stratified into limited disease (LD) and extent disease (ED) [3]. Twenty to $25 \%$ of patients have LD. For LD patients, chemotherapy plus thoracic radiotherapy followed by prophylactic cranial irradiation (PCI) is the standard treatment. Surgery is only available for a few early limited diseases (T1-2NOM0). The preferred treatment for ED patients is chemotherapy. Radiotherapy of the local lesion can effectively relieve symptoms [4]. Though

C C The Author(s). 2020 Open Access This article is licensed under a Creative Commons Attribution 4.0 International License, which permits use, sharing, adaptation, distribution and reproduction in any medium or format, as long as you give appropriate credit to the original author(s) and the source, provide a link to the Creative Commons licence, and indicate if changes were made. The images or other third party material in this article are included in the article's Creative Commons licence, unless indicated otherwise in a credit line to the material. If material is not included in the article's Creative Commons licence and your intended use is not permitted by statutory regulation or exceeds the permitted use, you will need to obtain permission directly from the copyright holder. To view a copy of this licence, visit http://creativecommons.org/licenses/by/4.0/. The Creative Commons Public Domain Dedication waiver (http://creativecommons.org/publicdomain/zero/1.0/) applies to the data made available in this article, unless otherwise stated in a credit line to the data. 
SCLC is initially highly sensitive to chemotherapy and radiotherapy, the response rates are around 60-80\% [5]. Most of patients have disease progression after treatment due to frequent resistance relapses $[6,7]$. Therefore, the 5-year survival rate remains low. The median survival times are 14-20 months and 7-10 months, and 5 -year survival rates are $15-25 \%$ and less than 5\% in LD and ED patients, respectively [7].

Limited progress had been made in more than two decades. Encouragingly, in recent years, immunotherapy was proved to play an important role in systemic therapy of ED-SCLC $[8,9]$. However, this therapy modality has not been generalized and data are limited. To increase the availability and therapeutic effect of present therapy modality and potential new treatment strategies, identification of predictive factors for survival is definitely needed. The predictive factors can help classify SCLC patients into subgroups with homogenous prognosis, which will benefit choice of treatment, studies of new therapy strategies, and comparison among studies of different medical centers.

Extent of disease and performance status (PS) have been identified as the most consistent prognostic clinical factors for survival [10-12]. Previous studies have reported various biomarkers of SCLC patients as candidates of prognostic factors, such as neuron-specific enolase (NSE), chromogranin A (cGA), neural cell adhesion molecule (NCAM), caspase cleaved cytokeratin 19 (CYFRA21.1), tissue polypeptide antigen (TPA), carcinoembryonic antigen (CEA), lactate dehydrogenase (LDH), and neutrophilto-lymphocyte ratio (NLR) [13, 14].

NSE, also known as enolase- $\gamma$, is a neuro- and neuroendocrine-specific isoenzyme of enolase, which is a key enzyme in aerobic glycolysis. NSE is localized to neurons and neuroendocrine cells of the amine precursor uptake and decarboxylation (APUD) series [15]. It is found in several neuroendocrine origin or neuronal tumors such as SCLC and neuroblastoma [13, 16]. Also, it is expressed in normal tissue, for example, neuroendocrine tissues, erythrocytes, smooth muscle cells, plasma cells, and platelets [17]. Early in the 1980s, researchers established cell lines from SCLC and demonstrated expression of NSE $[18,19]$. The levels of NSE in SCLC cell lines were significantly higher than those derived from other types of lung cancer [15]. Serum NSE level is reported to be frequently elevated in SCLC at the time of diagnosis, reduced after remission, and rebounded after relapse [20-22]. It made NSE a very important tumor marker of SCLC. Nowadays, NSE has become a widely used and easily attainable laboratory assay of SCLC patients. However, the prognostic value of NSE in SCLC patients remains controversial according to results from many researches. This study is to evaluate the prognostic significance of serum NSE in SCLC patients through systematic review with meta-analysis of the published literature.

\section{Material and methods Search strategy}

The PubMed, Cochrane Library, and Embase databases were searched from the inception dates to December 2019, to identify researches that meet the inclusion criteria of this review. There was no language restriction. The search terms were based on keywords, including "small cell lung cancer," "neuron-specific enolase," and "prognosis." The detailed search strategies are provided in the supplementary data. The reference lists of every article were checked for relevant articles. The protocol of this meta-analysis was open on PROSPERO, the International Prospective Register of Systematic Reviews (CRD42020160753).

\section{Inclusion and exclusion criteria}

Inclusion criteria for selecting were as follows: (i) the research subjects are SCLC patients confirmed by pathological or cytological examination; (ii) serum NSE was measured at least once before any therapy; (iii) a cutoff value of serum NSE was defined to dichotomize the level as "normal" or "high/abnormal/elevated" value; (iv) sufficient information to allow extracting directly or calculating the correlation of NSE with overall survival (OS) and/or progression-free survival (PFS), expressed by individual hazard ratio (HR) and its variance; and (v) if sample was overlapped in different published studies, only the most informative and recent research was included. The exclusion criteria were as follows: (i) duplicated articles and (ii) basic research, abstracts, letters, case reports, reviews, and other informally published forms.

\section{Data extraction and quality assessment}

Literature screening and identification were performed by two independent reviewers. If disagreement occurred, two authors discussed and arrived at consensus with a third author. The following information from each study was recorded: first author, publication year, study design, source of patient, sample sizes, age of patients, gender of patients, extent of disease, cutoff value of the serum NSE, treatment protocol, follow-ups, and outcome data (OS, PFS, and corresponding effect sizes). If data from any of the above categories were not given in the primary studies, items were treated as "not applicable."

Quality assessment of the included studies was conducted using the Newcastle-Ottawa Scale (NOS). The NOS consists of three parts: selection ( $0-4$ points), comparability ( $0-2$ points), and outcome assessment $(0-3$ points). Two independent reviewers assessed the risk of bias of each study. Disagreement was resolved by 
discussion or consultation with an independent third adjudicator.

\section{Statistical analysis}

The primary endpoint was OS, which was defined as the interval from treatment until time of death from any cause. The secondary endpoint was PFS, which was defined as the interval from treatment until time of first progression or death from any cause. The effect sizes namely $\mathrm{HR}$ and $95 \% \mathrm{CI}$ of the dichotomous variable ("normal" or "high" level of serum NSE) were obtained directly from each literature. If the HRs were not available, we calculated the effect sizes using other survival data according to the methods illustrated by Tierney et al. [23]. A HR $>1$ indicated a worse prognosis in SCLC patients with elevated level of NSE before treatment. Cochran's $Q$ test and Higgins' $I^{2}$ statistic were conducted to assess the heterogeneity of the included researches. If $I^{2}$ was $>50 \%$, a substantial level of heterogeneity may exist among these researches, in which case a random effect model was used. Otherwise, a fixed effect model was used. In cases of substantial heterogeneity, we performed subgroup analysis for OS according to study design, ethnicity, cutoff value of NSE, and treatment protocol and conducted meta-regression to explore and explain the probable source of heterogeneity. We also conducted sensitivity analysis to assess the influence of individual study to the overall effect size estimate. Publication bias was assessed by Egger's linear regression and Begg's funnel plot [24]. A two-sided $p$ value $<0.05$ was considered statistically significant. Data combination and statistical analyses were performed using the Review Manager (RevMan) software (V.5.3, Cochrane Collaboration) and Stata/SE version 14.0 for Windows (StataCorp, College Station, TX, USA).

\section{Result}

\section{Study characteristics}

The process for identification of eligible articles is shown in Fig. 1. A total of 492 items were identified (212 from PubMed, 262 from Embase, and 18 from the Cochrane library). After meticulous screening and inspection of the articles, finally, 18 articles were included in our final analysis [21, 25-41].

Table 1 summarizes the characteristics of the included studies. The total number of patients in our systematic review and meta-analysis was 2981. All studies were published between 1991 and 2019. Sixteen of all 18 studies were retrospective studies. In the rest two studies, sample of Bremnes et al.'s study [31] was comprised of patients included in another prospective multicenter study [42], while Liu et al.'s study [39] was a prospective single-armed study. Treatment protocol " $C$ " refers to that patients received only chemotherapy, " $C, R$ " refers to that patients received chemotherapy with or without radiotherapy, and "S,C,R" refers to that part of patients received surgical resection before chemotherapy and radiotherapy. Effect sizes of correlation between serum level of NSE and OS were available in 16 studies, while those between serum level of NSE and PFS were available in only 4 studies. NOS scores of all studies were $\geq 6$ stars.

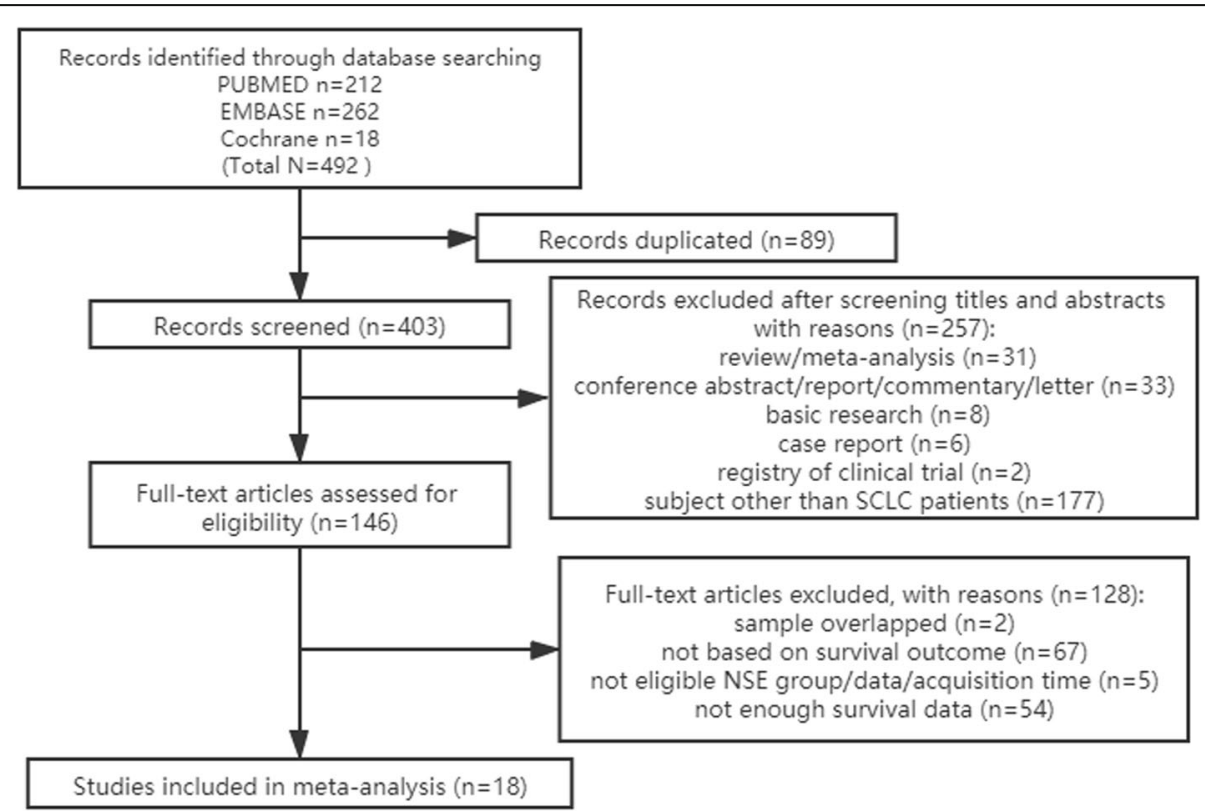

Fig. 1 Flow diagram for identification of eligible studies 
Table 1 Main characteristics of studies included in the meta-analysis

\begin{tabular}{|c|c|c|c|c|c|c|c|c|c|c|c|c|c|}
\hline Study & Year & Study design & Ethnicity & $N$ & $\begin{array}{l}\text { Percentage } \\
\text { of LD-SCLC }\end{array}$ & $\begin{array}{l}\text { Percentage of } \\
\text { male patients }\end{array}$ & $\begin{array}{l}\text { Age } \\
\text { (median) }\end{array}$ & $\begin{array}{l}\text { Age } \\
\text { (mean) }\end{array}$ & $\begin{array}{l}\text { Age } \\
\text { (range) }\end{array}$ & $\begin{array}{l}\text { Cutoff of NSE } \\
(\mathrm{ng} / \mathrm{ml})\end{array}$ & Treatment & Outcome & NOS \\
\hline $\begin{array}{l}\text { van der } \\
\text { Gaast A } \\
{[25]}\end{array}$ & 1991 & Retrospective & Caucasian & 70 & $41.4 \%$ & $77.1 \%$ & 63 & & $36-75$ & 12.5 & C & OS & 7 \\
\hline $\begin{array}{l}\text { Johnson } \\
\text { PW [26] }\end{array}$ & 1993 & Retrospective & Caucasian & 154 & $29.2 \%$ & $65.0 \%$ & 63 & & $34-77$ & 25 & $C, R$ & OS & 7 \\
\hline $\begin{array}{l}\text { Fischer JR } \\
{[27]}\end{array}$ & 1997 & Retrospective & Caucasian & 52 & $63.5 \%$ & $75.0 \%$ & & 58 & $36-75$ & 30 & $C, R$ & OS & 6 \\
\hline $\begin{array}{l}\text { Shibayama } \\
\text { T }[28]\end{array}$ & 2001 & Retrospective & Asian & 114 & $59.1 \%$ & $86.8 \%$ & 65 & & $29-82$ & 7.5 & $C, R$ & OS & 6 \\
\hline Jin B [29] & 2001 & Retrospective & Asian & 144 & NA & $85.4 \%$ & 62.12 & & $36-86$ & 12.5 & C & OS & 6 \\
\hline $\begin{array}{l}\text { Jean-Louis } \\
\text { Pujol [30] }\end{array}$ & 2003 & Retrospective & Caucasian & 148 & $39.2 \%$ & $93.9 \%$ & 63 & 61 & $42-82$ & 17 & $C, R$ & OS & 7 \\
\hline $\begin{array}{l}\text { Bremnes } \\
\text { RM [31] }\end{array}$ & 2003 & Prospective & Caucasian & 436 & $49.1 \%$ & $64.2 \%$ & 64 & & $39-76$ & 13 & $C, R$ & OS & 7 \\
\hline $\begin{array}{l}\text { Ando S } \\
{[32]}\end{array}$ & 2004 & Retrospective & Asian & 57 & $64.9 \%$ & $84.2 \%$ & & 66 & $48-78$ & 10.5 & $S, C, R$ & OS & 6 \\
\hline Xue F [33] & 2011 & Retrospective & Asian & 57 & $52.6 \%$ & $68.4 \%$ & 52.5 & & $29-70$ & 15.2 & $C, R$ & OS & 6 \\
\hline Zhu H [34] & 2015 & Retrospective & Asian & 281 & $55.5 \%$ & $80.4 \%$ & 57 & & $25-82$ & 18 & $S, C, R$ & OS & 7 \\
\hline $\begin{array}{l}\text { Huang Z } \\
{[21]}\end{array}$ & 2016 & Retrospective & Asian & 122 & $44.3 \%$ & $75.4 \%$ & NA & NA & NA & 17 & $C, R$ & PFS & 6 \\
\hline $\begin{array}{l}\text { Wojcik E } \\
\text { [35] }\end{array}$ & 2016 & Retrospective & Caucasian & 63 & $65.1 \%$ & $60.3 \%$ & 59 & & $32-76$ & 35 & $C, R$ & OS & 6 \\
\hline Jiang X [36] & 2017 & Retrospective & Asian & 107 & $39.3 \%$ & $78.5 \%$ & 63 & & $\begin{array}{l}58.5- \\
68\end{array}$ & 17 & $C, R$ & OS & 7 \\
\hline Pan H [37] & 2017 & Retrospective & Asian & 275 & NA & $87.0 \%$ & & 62.59 & & 81.4 & $C, R$ & OS & 7 \\
\hline $\begin{array}{l}\text { Zhou M } \\
\text { [38] }\end{array}$ & 2017 & Retrospective & Asian & 523 & $26.8 \%$ & $79.3 \%$ & 59 & & $27-87$ & & $C, R$ & OS & 7 \\
\hline Liu X [39] & 2017 & Prospective & Asian & 136 & $43.4 \%$ & $64.7 \%$ & & 53.3 & & 50.324 & $C, R$ & OS, PFS & 6 \\
\hline $\begin{array}{l}\text { Zhang C } \\
{[40]}\end{array}$ & 2018 & Retrospective & Asian & 160 & $23.8 \%$ & $80.6 \%$ & 59 & & $23-83$ & & C & PFS & 7 \\
\hline Fan S [41] & 2019 & Retrospective & Asian & 82 & NA & $81.7 \%$ & 60 & & $28-82$ & 16.3 & $C, R$ & OS, PFS & 7 \\
\hline
\end{tabular}

Abbreviations: $L D-S C L C$ limited disease small cell lung cancer, $C$ chemotherapy, $R$ radiotherapy, $S$ surgery, OS overall survival, $P F S$ progression-free survival, $N A$ not available

\section{NSE and OS in SCLC}

Meta-analysis was conducted on 16 studies with effect size data of OS. However, the heterogeneity was moderate $\left(I^{2}=56 \%, Q=33.74, p=0.004\right)$; therefore, pooled estimates were weighted and combined using a random effect model. The results indicated that elevated NSE predicted a poorer OS for SCLC patients, with the combined HR of 1.78 (95\% CI 1.55-2.06, $p<0.001$; Fig. 2).

In the subgroup analysis for OS according to treatment protocol, elevated NSE did not have significant prognostic value of OS for SCLC patients treated by only chemotherapy in 2 studies $[25,29]$ with combined HR of 1.22 (95\% CI 0.96-1.55, $p=0.10 ; I^{2}=0 \%, p=0.32$ ). In addition, elevated NSE did not have significant prognostic value of OS for SCLC patients part of whom received surgical resection before chemotherapy and radiotherapy in 2 studies [32, 34] with combined HR of 2.16 (95\% CI 0.82-5.69, $p=0.12 ; I^{2}=75 \%$ ), while the combined HR of the remaining 13 studies indicated that elevated NSE may predict worse OS (HR 1.90, 95\% CI 1.63-2.20, $p<$ $0.001 ; I^{2}=48 \%, p=0.03$ ) in SCLC patients who received chemotherapy with or without radiotherapy.

The meta-regression technique performed using the model weighted by the inverse of the variance was also used to explore the source heterogeneity. We investigated study design, ethnicity, cutoff value of NSE, and treatment as probable sources of heterogeneity, and there were no significant factors identified (coefficient 0.96, 95\% CI $0.45-1.46$; coefficient 0.96 , 95\% CI $0.57-$ 1.36; coefficient $1.01,95 \%$ CI $0.63-1.39$; coefficient 0.89 , 95\% CI 0.61-1.18; respectively).

We also performed sensitivity analysis to investigate the influence of each study on the overall meta-analysis estimate by calculating the pooled HRs with successive exclusion of one study. None of these studies had a significant interference to combined HRs than the other studies (Fig. 3). 


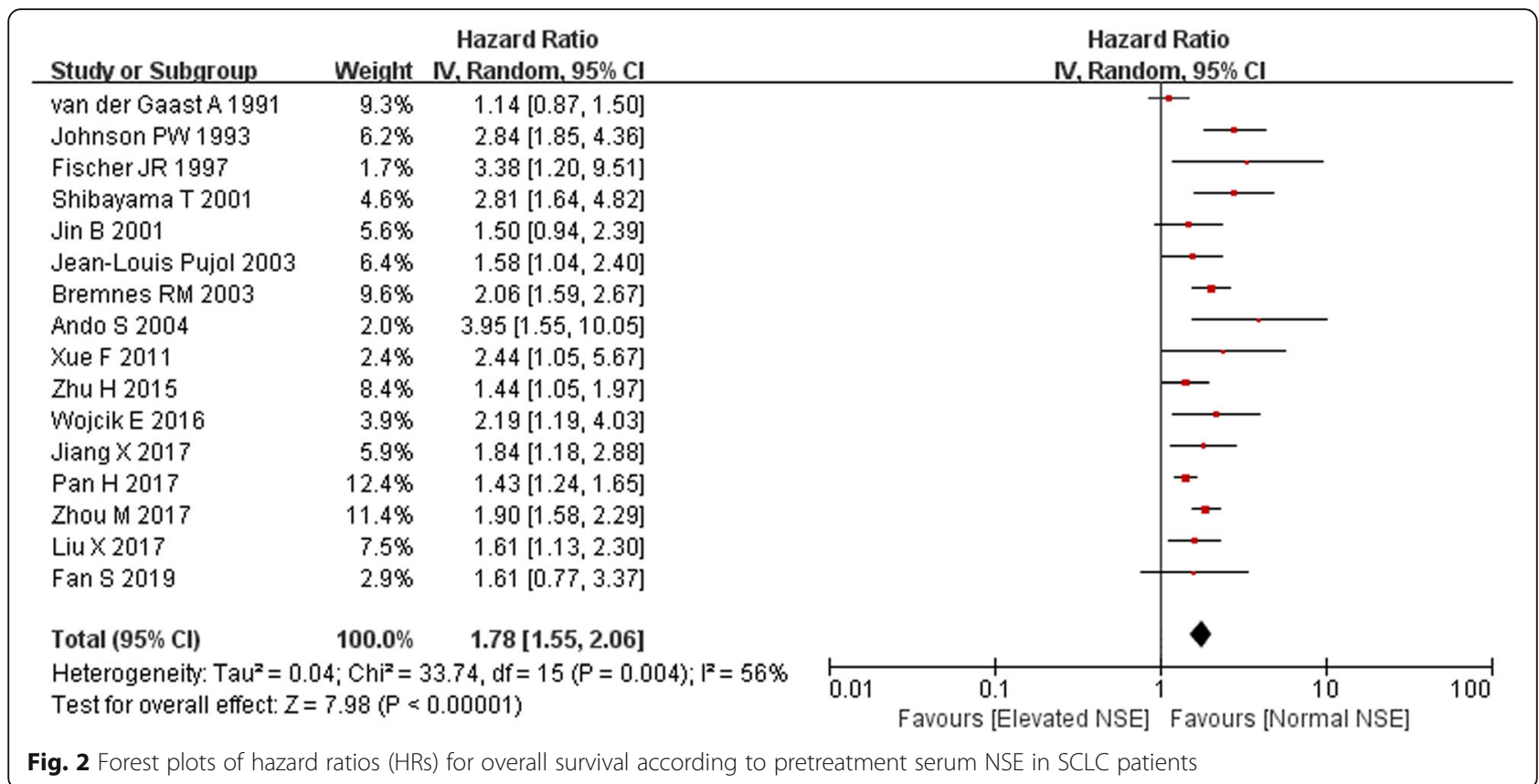

\section{NSE and PFS in SCLC}

Meta-analysis was conducted on 4 studies with effect size data of PFS. The heterogeneity was mild $\left(I^{2}=\right.$ $37.0 \%, Q=4.76, p=0.19)$; therefore, pooled estimates were weighted and combined using a fixed effect model. The results indicated that elevated NSE predicted a poorer PFS for SCLC patients, with the combined HR of 1.50 (95\% CI 1.16-1.93, $p=0.002$; Fig. 4).

\section{Publication bias}

Egger's linear regression test and Begg's funnel plot were performed to evaluate publication bias. Publication bias was detected for OS by Egger's test $(p=0.04)$, but not detected by Begg's test $(p=0.10)$.

\section{Discussion}

In this study, we investigated the prognostic value of serum NSE before therapy in SCLC patients using a systemic review and meta-analysis approach. The combined HR from 16 of the included studies indicated that elevated serum NSE may predict worse OS (HR 1.78, 95\% CI $1.55-2.06, p<0.001)$. In addition, the combined HR from 4 of the included studies revealed that elevated serum NSE may also predict poorer PFS (HR 1.50, 95\%

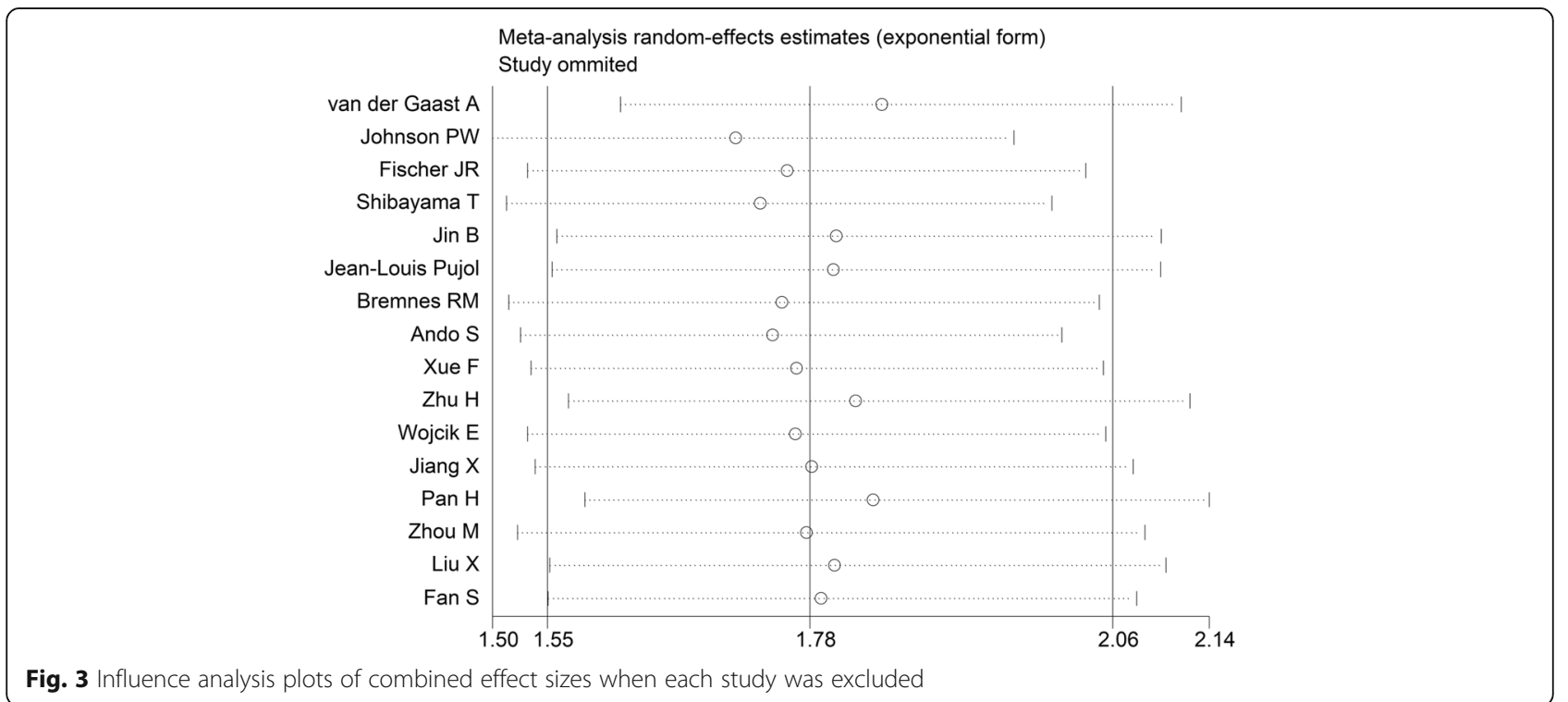




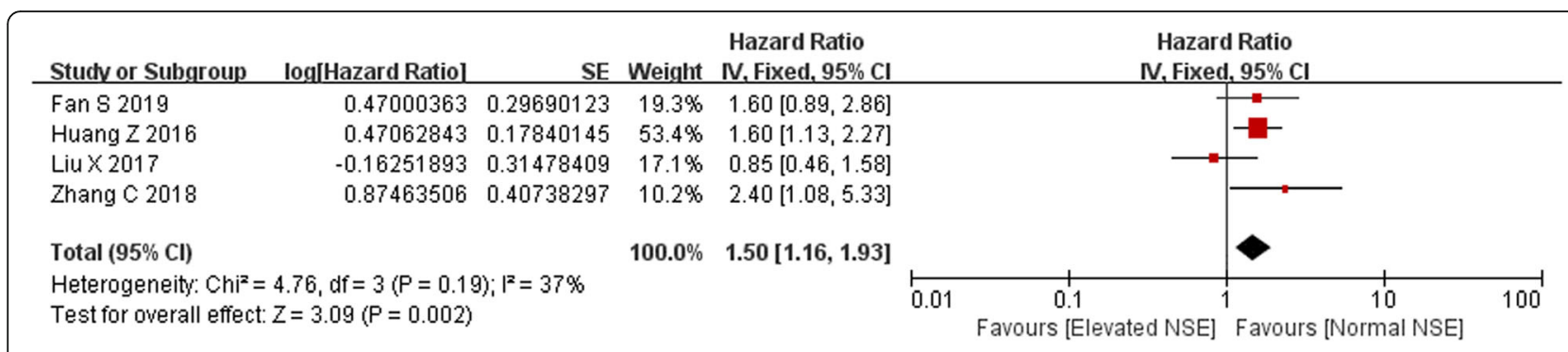

Fig. 4 Forest plots of hazard ratios (HRs) for progression-free survival according to pretreatment serum NSE in SCLC patients

CI $1.16-1.93, p=0.002)$. Serum NSE could be secreted by SCLC tumor cells, and its level is related to tumor mass extension $[22,43]$. Thus, serum NSE level is associated with the tumor burden. Liu's team silenced NSE in SCLC cell lines using a loss-of-function approach and found that the knockdown of NSE suppressed proliferation, colony formation, and migration of SCLC cells, compared to those of the control group. Also, the silencing of NSE led to the downregulation of metastasis promoter gene vascular endothelial growth factor (VEGF) and upregulation of metastasis suppressor genes NM23 and E-cadherin [44]. These experimental results may support that the elevated NSE of SCLC patients is associated with unfavorable outcome.

Subgroup analysis was conducted yet failed to find the source of heterogeneity. In subgroup analysis for OS according to treatment protocol, the prognostic value of serum NSE for OS was only observed in SCLC patients treated by chemotherapy with or without radiotherapy. Our interpretations for the results of the subgroup analysis are as follows. First, the number of studies included in the other two subgroups was limited, which may cause limited sample size and restrict the statistic power. Secondly, chemotherapy and radiotherapy are standard treatment modality for most of SCLC patients [4.] Only a very limited part $(<5 \%)$ of patients had opportunity to receive surgical resection [4]. The relatively high proportion of surgical management in the 2 studies [32, 34] of the subgroup S,C,R may impair the representativeness of sample. Likewise, patients in the 2 studies $[25,29]$ of the subgroup $\mathrm{C}$ received only chemotherapy, but they did not detail the reason. Thirdly, in clinical practice, the prognostic value of NSE may only be expressed on condition that patients received standard management.

Moderate heterogeneity for the outcomes of interest existed in this meta-analysis. Although we investigated potential sources of heterogeneity, they were not identified in meta-regression analysis. In addition, the result of sensitivity analysis implied that each individual study did not have significant influence to overall combined HR.

Limited by the rather low incidence of SCLC, the existing studies were almost retrospective. Due to the relatively limited quality of studies, only officially published studies can be included, though we performed the literature search as thoroughly as possible to minimize publication bias. However, Egger's test and the asymmetric funnel plot implied that the publication bias cannot be excluded. In sensitivity analysis, we also performed a trim and fill method to evaluate the stability of combined HR. Figure 5 reveals that 5 studies were needed to counteract the publication bias. However, when the 5 studies were added, the combined HR did not change significantly (HR 1.61, 95\% CI 1.38-1.87, $p<$ 0.001 ). It indicated that the publication bias may not affect the result.

Watine [45] published a systematic review in 1999 and tried to establish laboratory parameters including NSE, to give the pretreatment prognostic information in small cell lung cancer (SCLC) patients. However, the prognostic value of NSE was not demonstrated at that time. A meta-analysis of similar theme was published in 2013 [46]. But this meta-analysis only assessed the impact of NSE on OS. What is more, since then, there were still original researches with negative results published [41]. The prognostic value of NSE still remains controversial. Our meta-analysis was not only an update. We also performed subgroup analysis to evaluate the condition of applying NSE. Meta-regression was also adopted to explore the source of heterogeneity. Sensitivity analysis was performed to evaluate the stability of result. Furthermore, the trim and fill method was used to evaluate the influence of publication bias.

Several potential limitations of our study should be considered when interpreting the results. Firstly, most of the included studies were retrospective, which were more susceptible to some biases. Secondly, different thresholds of serum NSE level and detection technologies were adopted in these studies. Though NSE in these studies was dichotomized according to the threshold value, the bias was non-negligible. Third, we combined the HRs from univariate analysis using Cox proportional hazard model of each study, which were unadjusted for other factors, because HR from multivariate analysis was adjusted with different kinds and number of factors and regressed by different models in individual study, which may sometimes be excluded from model and cause more 


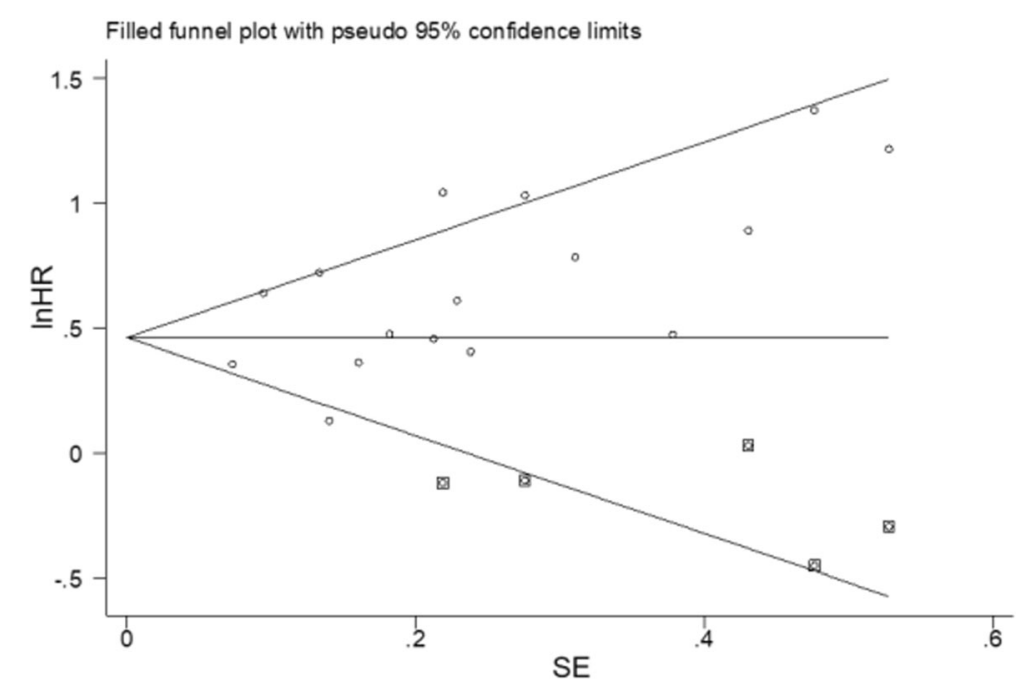

Fig. 5 Funnel plot after trim and fill method. The small circles on the plot refer to the 16 studies included in the meta-analysis for correlation between serum NSE and OS, while the small diamonds on the plot refer to the 5 hypothetic studies needed to trim the plot to make it symmetric

bias. Finally, there was a statistically significant heterogeneity in the included studies and publication bias cannot be excluded.

\section{Conclusion}

Elevated serum NSE before any therapy of SCLC patients may be a negative prognostic factor for OS and PFS. The prognostic value of NSE for OS was particularly observed in patients treated by standard management. Further trials of high evidence level are needed to sustain the conclusion.

\section{Supplementary information}

Supplementary information accompanies this paper at https://doi.org/10. 1186/s12957-020-01894-9.

Additional file 1:. Supplement data-search strategy

\section{Abbreviations}

SCLC: Small cell lung cancer; NSCLC: Non-small cell lung cancer; LD: Limited disease; ED: Extent disease; PCl: Prophylactic cranial irradiation; PS: Performance status; NSE: Neuron-specific enolase; cGA: Chromogranin A; NCAM: Neural cell adhesion molecule: CYFRA21.1: Caspase cleaved cytokeratin 19; TPA: Tissue polypeptide antigen; CEA: Carcinoembryonic antigen; LDH: Lactate dehydrogenase; NLR: Neutrophil-to-lymphocyte ratio; OS: Overall survival; PFS: Progression-free survival; HR: Hazard ratio; Cl: Confidence interval; NOS: Newcastle-Ottawa Scale; APUD: Amine precursor uptake and decarboxylation; VEGF: Vascular endothelial growth factor

\section{Acknowledgements}

None.

\section{Authors' contributions}

QGL conceived this research. TZJY performed the design. TZJY, WHS, and FHX performed the literature search, study inclusion, and data extraction. TZJY, ZZR, MQL, LDR, and LCY performed the data analysis and interpretation. TZJY and QGL drafted and revised the manuscript. All authors reviewed and approved the final manuscript.

\section{Funding}

This research did not receive any specific grant from funding agencies in the public, commercial, or not-for-profit sectors.

\section{Availability of data and materials}

The data used and analyzed in the current study are available from the corresponding author upon reasonable request.

\section{Ethics approval and consent to participate}

Not applicable.

\section{Consent for publication}

Not applicable.

\section{Competing interests}

The authors declare that they have no competing interests.

Received: 12 February 2020 Accepted: 21 May 2020

Published online: 30 May 2020

\section{References}

1. Bray F, Ferlay J, Soerjomataram I, Siegel RL, Torre LA, Jemal A: Global cancer statistics 2018: GLOBOCAN estimates of incidence and mortality worldwide for 36 cancers in 185 countries. CA Cancer J Clin 2018, 68:394-424.

2. Gazdar AF, Bunn PA, Minna JD. Small-cell lung cancer: what we know, what we need to know and the path forward. Nat Rev Cancer. 2017;17:725-37.

3. Micke P, Faldum A, Metz T, Beeh KM, Bittinger F, Hengstler JG, et al. Staging small cell lung cancer: Veterans Administration Lung Study Group versus International Association for the Study of Lung Cancer--what limits limited disease? Lung Cancer. 2002;37:271-6.

4. Jett JR, Schild SE, Kesler KA, Kalemkerian GP. Treatment of small cell lung cancer: diagnosis and management of lung cancer, 3rd ed: American College of Chest Physicians evidence-based clinical practice guidelines. Chest. 2013;143:e400S-19S

5. Faivre C, El Cheikh R, Barbolosi D, Barlesi F. Mathematical optimisation of the cisplatin plus etoposide combination for managing extensive-stage small-cell lung cancer patients. Br J Cancer. 2017;116:344-8.

6. van Meerbeeck JP, Fennell DA, De Ruysscher DK. Small-cell lung cancer. Lancet. 2011;378:1741-55. 
7. El Maalouf G, Rodier JM, Faivre S, Raymond E. Could we expect to improve survival in small cell lung cancer? Lung Cancer. 2007;57(Suppl 2):S30-4.

8. Horn L, Mansfield AS, Szczesna A, Havel L, Krzakowski M, Hochmair MJ, et al. First-line atezolizumab plus chemotherapy in extensive-stage small-cell lung cancer. N Engl J Med. 2018;379:2220-9.

9. Paz-Ares L, Dvorkin M, Chen Y, Reinmuth N, Hotta K, Trukhin D, et al. Durvalumab plus platinum-etoposide versus platinum-etoposide in first-line treatment of extensive-stage small-cell lung cancer (CASPIAN): a randomised, controlled, open-label, phase 3 trial. Lancet. 2019;394:1929-39.

10. Coates A, Porzsolt F, Osoba D. Quality of life in oncology practice: prognostic value of EORTC QLQ-C30 scores in patients with advanced malignancy. Eur J Cancer. 1997;33:1025-30.

11. Sorensen M, Pijls-Johannesma M, Felip E. Small-cell lung cancer: ESMO Clinical Practice Guidelines for diagnosis, treatment and follow-up. Ann Oncol. 2010;21(Suppl 5):v120-5.

12. Li J, Dai CH, Chen P, Wu JN, Bao QL, Qiu H, et al. Survival and prognostic factors in small cell lung cancer. Med Oncol. 2010;27:73-81.

13. Harmsma M, Schutte B, Ramaekers FC. Serum markers in small cell lung cancer: opportunities for improvement. Biochim Biophys Acta. 1836;2013: 255-72

14. Kang MH, Go SI, Song HN, Lee A, Kim SH, Kang JH, et al. The prognostic impact of the neutrophil-to-lymphocyte ratio in patients with small-cell lung cancer. Br J Cancer. 2014;111:452-60.

15. Marangos PJ, Gazdar AF, Carney DN. Neuron specific enolase in human small cell carcinoma cultures. Cancer Lett. 1982;15:67-71.

16. Zeltzer PM, Marangos PJ, Parma AM, Sather H, Dalton A, Hammond D, et al. Raised neuron-specific enolase in serum of children with metastatic neuroblastoma. A report from the Children's Cancer Study Group. Lancet. 1983:2:361-3.

17. Massabki PS, Silva NP, Lourenco DM, Andrade LE. Neuron specific enolase concentration is increased in serum and decreased in platelets of patients with active systemic sclerosis. J Rheumatol. 2003;30:2606-12.

18. Gazdar AF, Carney DN, Nau MM, Minna JD. Characterization of variant subclasses of cell lines derived from small cell lung cancer having distinctive biochemical, morphological, and growth properties. Cancer Res. 1985;45:2924-30.

19. Carney DN, Gazdar AF, Bepler G, Guccion JG, Marangos PJ, Moody TW, et al. Establishment and identification of small cell lung cancer cell lines having classic and variant features. Cancer Res. 1985;45:2913-23.

20. Jaques $G$, Auerbach B, Pritsch M, Wolf M, Madry N, Havemann K. Evaluation of serum neural cell adhesion molecule as a new tumor marker in small cell lung cancer. Cancer. 1993;72:418-25.

21. Huang $Z$, Xu D, Zhang F, Ying Y, Song L. Pro-gastrin-releasing peptide and neuron-specific enolase: useful predictors of response to chemotherapy and survival in patients with small cell lung cancer. Clin Transl Oncol. 2016;18: 1019-25.

22. Carney DN, Marangos PJ, Ihde DC, Bunn PA Jr, Cohen MH, Minna JD, et al. Serum neuron-specific enolase: a marker for disease extent and response to therapy of small-cell lung cancer. Lancet. 1982;1:583-5.

23. Tierney JF, Stewart LA, Ghersi D, Burdett S, Sydes MR. Practical methods for incorporating summary time-to-event data into meta-analysis. Trials. 2007:8:16.

24. Egger M, Davey Smith G, Schneider M, Minder C. Bias in meta-analysis detected by a simple, graphical test. BMJ. 1997:315:629-34.

25. van der Gaast A, van Putten WL, Oosterom R, Cozijnsen M, Hoekstra Splinter RTAW. Prognostic value of serum thymidine kinase, tissue polypeptide antigen and neuron specific enolase in patients with small cell lung cancer. Br J Cancer. 1991;64:369-72.

26. Johnson PW, Joel SP, Love S, Butcher M, Pandian MR, Squires L, et al. Tumour markers for prediction of survival and monitoring of remission in small cell lung cancer. Br J Cancer. 1993;67:760-6.

27. Fischer JR, Schindel M, Bulzebruck H, Lahm H, Krammer PH, Drings P. Decrease of interleukin-2 secretion is a new independent prognostic factor associated with poor survival in patients with small-cell lung cancer. Ann Oncol. 1997;8:457-61.

28. Shibayama T, Ueoka H, Nishii K, Kiura K, Tabata M, Miyatake K, et al. Complementary roles of pro-gastrin-releasing peptide (ProGRP) and neuron specific enolase (NSE) in diagnosis and prognosis of small-cell lung cancer (SCLC). Lung Cancer. 2001;32:61-9.

29. Jin B, Zhao $L$, Zhou C. The prognostic value of serum neuron specific enolase detection in small cell lung cancer. Zhonghua Jie He He Hu Xi Za Zhi. 2001;24:722-4.
30. Pujol JL, Quantin X, Jacot W, Boher JM, Grenier J, Lamy PJ. Neuroendocrine and cytokeratin serum markers as prognostic determinants of small cell lung cancer. Lung Cancer. 2003;39:131-8.

31. Bremnes RM, Sundstrom S, Aasebo U, Kaasa S, Hatlevoll R, Aamdal S. The value of prognostic factors in small cell lung cancer: results from a randomised multicenter study with minimum 5 year follow-up. Lung Cancer. 2003;39:303-13.

32. Ando $S$, Suzuki M, Yamamoto $N$, lida $T$, Kimura $H$. The prognostic value of both neuron-specific enolase (NSE) and Cyfra21-1 in small cell lung cancer. Anticancer Res. 2004;24:1941-6.

33. Xue F, Wang $L$, Zhang $M$, Cai $L$. Clinical significance of detection of serum values of neuron specific enolase before and after treatment for small cell lung cancer. Zhongguo Fei Ai Za Zhi. 2011;14:723-6.

34. Zhu H, Guo H, Li M, Zhang Y, Han A, Shi F, et al. Increased serum carcinoembryonic antigen level can predict poor survival of patients with small cell lung cancer. Transl Res. 2015;166:355-65.

35. Wojcik E, Tarapacz J, Rychlik U, Stasik Z, Sas-Korczynska B, Skotnicki P, et al. Human epididymis protein 4 (HE4) in patients with small-cell lung cancer. Clin Lab. 2016;62:1625-32.

36. Jiang $X$, Mei $X, W u H$, Chen X. D-dimer level is related to the prognosis of patients with small cell lung cancer. Ann Transl Med. 2017;5:394.

37. Pan $H$, Shi $X$, Xiao D, He J, Zhang $Y$, Liang $W$, et al. Nomogram prediction for the survival of the patients with small cell lung cancer. J Thorac Dis. 2017:9:507-18.

38. Zhou M, Wang Z, Yao Y, Zhou H, Liu M, Sun J. Neuron-specific enolase and response to initial therapy are important prognostic factors in patients with small cell lung cancer. Clin Transl Oncol. 2017;19:865-73.

39. Liu X, Zhang W, Yin W, Xiao Y, Zhou C, Hu Y, et al. The prognostic value of the serum neuron specific enolase and lactate dehydrogenase in small cell lung cancer patients receiving first-line platinum-based chemotherapy. Medicine (Baltimore). 2017;96:e8258.

40. Zhang C, Jia Y, Jia Y, Zhang X, Li K. Prognostic and predictive value of plasma D-dimer levels in patients with small-cell lung cancer. Int J Clin Oncol. 2018;23:1070-5.

41. Fan S, Zhao G, An G. High pretreatment plasma D-dimer levels are associated with shorter overall survival in patients with small cell lung cancer. J Int Med Res. 2019:47:215-24.

42. Sundstrøm S, Bremnes RM, Kaasa S, Aamdal S: Cisplatin and etoposide (EPregimen) is superior to cyclophosphamide, epirubicin, and vincristin (CEVregimen) in small cell lung cancer: results from a randomized phase III trial with 5 years follow-up. 2001, 37:S153-S153.

43. Giovanella L, Piantanida R, Ceriani L, Bandera M, Novario R, Bianchi L, et al. Immunoassay of neuron-specific enolase (NSE) and serum fragments of cytokeratin 19 (CYFRA 21.1) as tumor markers in small cell lung cancer: clinical evaluation and biological hypothesis. Int J Biol Markers. 1997;12:226.

44. Liu X, Liu S, Fu J, Huang J, Weng C, Fang X, et al. Knockdown of neuronspecific enolase suppresses the proliferation and migration of $\mathrm{NCl}-\mathrm{H} 209$ cells. Oncol Lett. 2019;18:4809-15.

45. Watine J. Laboratory variables as additional staging parameters in patients with small-cell lung carcinoma. A systematic review. Clin Chem Lab Med. 1999;37:931-8.

46. Zhao WX, Luo JF. Serum neuron-specific enolase levels were associated with the prognosis of small cell lung cancer: a meta-analysis. Tumour Biol. 2013:34:3245-8.

\section{Publisher's Note}

Springer Nature remains neutral with regard to jurisdictional claims in published maps and institutional affiliations. 